\title{
Образ артиста у представителей профессии и любителей сценического искусства: анадиз стереотипных представдений
}

\author{
Наталья Е. Комерова*, Анастасия В. Гришина \\ Донской государственный технический университет, Ростов-на-Дону, Российская \\ Федерация \\ *E-mail: komerova.nata@gmail.com \\ *ORCID: https://orcid.org/0000-0001-7129-3320
}

\begin{abstract}
Аннотация
Статья посвящена изучению образа профрессионального артиста посреАством исследования стереотипных преАставлений о наличии, ^ибо отсутствии опреде-

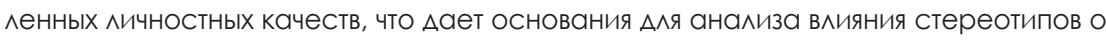
профессии на восприятие личности в целом. Новизна заключается в рассмотрении стереотипных представлений самих артистов о том, какими качествами Аолжен облалать «типичный» преАставитель актерской профрессии. Во ввеАении рассматриваются основные представления о личности профрессионального артиста. Проанализированы исследования зарубежных и отечественных ученых в области психологии творчества, сценического искусства. Выводы театральных пеАагогов, искусствовеАов, режиссеров имеют огромную практическую ценность А^я осмысления ^ичности артиста и сценической Аеятельности в контексте психологической науки. Основными методами исслеАования выбраны «Анкета биполярных профрилей» Т. Г. Стедраненко (в модифоикации Гришиной А. В., Комеровой Н. Е.) и анализ полученных $А$ анных с помощью статистического критерия U-Манна-Уитни. Результаты сравнительного анализа исследования Авух групп (артистов профрессионального театра и ^юбителей сценического искусства) позволили выявить наиболее характерные А^я представителей продрессии артиста условно «положительные» и условно «отрицательные» качества. Проведена оценка схожести и различия мнений респондентов относительно наличия Аанных качеств у «типичного» актера. В
\end{abstract} ОбсужАении результатов слеланы выводы, что представления об образе артиста у обеих групп испытуемых схожи в части наличия у профрессионального артиста высокого эмоциона^ьного Интем^екта, оптИмизма, эмоциона^ьной возбУАИмости, высокой работоспособности, но имеют различия относитеАьно таких свойств ^ичности, как высокая самооценка, ^ень, тщеславие, пессимизм. Получены статистически значимые различия в оценке уровня тщеславия у представителей профрессии. Так, профрессиональные артисты считают, что артист менее тщеславен и более ^енив, чем его оценивают ^юбители сценического искусства. 
ОБЩАЯ ПСИХОЯОГИЯ, ПСИХОЯОГИЯ ЯИЧНОСТИ, ИСТОРИЯ ПСИХОЯОГИИ

\title{
КАючевые слова
}

образ артиста, профрессиональный актер, стереотипные представления, восприимчивость, искусство, творчество, профеессия, тщеславие

\section{Для цитирования}

Комерова Н. Е., Гришина А. В. Образ артиста у представителей профессии и любителей сценического искусства: анализ стереотипных представлений // Инновационная наука: психодогия, педагогика, дефектология. 2021. Т. 4, № 5. C. 37-47. doi: https://doi.org/10.23947/2658-7165-2021-4-5-37-47

\section{The image of an artist among representatives of the profession and amateurs of performing arts: analysis of stereotypical representations}

\author{
Natalia E. Komerova, Anastasia V. Grishina \\ Don State Technical University, Rostov-on-Don, Russian Federation \\ *E-mail: komerova.nata@gmail.com \\ *ORCID: https://orcid.org/0000-0001-7129-3320
}

\begin{abstract}
The article is devoted to the study of the image of a professional artist through the study of stereotyped ideas about the presence or absence of certain personal qualities. The novelty lies in the consideration of the stereotypical ideas of the artists themselves about what qualities a "typical" representative of the acting profession should have. The Introduction examines the basic ideas about the personality of a professional artist. Analyzed the research of foreign and domestic scientists in the field of psychology of creativity, performing arts. So, the study of the artist's personality mainly took place in the plane of art and creativity. The conclusions of theater teachers, art historians, directors are of great practical value for understanding the personality of an artist and stage activity in the context of psychological science. The main research methods were selected "Questionnaire of bipolar profiles" by T. G. Stefanenko (modified by A. V. Grishina, N. E. Komerova) and analysis of the data obtained using the U-Mann-Whitney statistical test. The Results of a comparative analysis of the study of two groups (artists of professional theater and amateurs of theatrical art) made it possible to identify the conditionally "positive" and conditionally "negative" qualities most characteristic of the representatives of the artist's profession. The assessment of the similarities and differences of opinions of the respondents regarding the presence of these qualities in a "typical" actor was carried out. In the Discussion, it was concluded that the ideas about the image of an artist in both groups of subjects are similar in terms of the presence of a professional artist of high emotional intelligence, optimism, emotional excitability, high performance, but they have
\end{abstract}


differences regarding such personality traits as high self-esteem, laziness, vanity, pessimism. Statistically significant differences were obtained in assessing the level of vanity among representatives of the profession. For example, professional artists believe that an artist is less vain and lazier than lovers of performing arts estimate him.

\section{Keywords}

artist image, professional actor, stereotypes, receptivity, art, creativity, profession, vanity

\section{For citation}

Komerova N. E., Grishina A. V. The image of an artist among representatives of the profession and amateurs of performing arts: analysis of stereotypical representations. Innovative Science: psychology, pedagogy, defectology, 4(5), 37-47. doi: https://doi. org/10.23947/2658-7165-2021-4-5-37-47

\section{Введение}

Изучение образа профессионального артиста в контексте стереотипных представлений весьма интересная и актуальная область для исследования, поскольку она позволяет узнать наиболее общие представления людей об определенных аспектах человеческой жизни. Воздействие стереотипов на восприятие действительности, мышление человека, а, следовательно, и на его поведение очень ведико. С одной стороны, это облегчает жизнь и избавляет от необходимости постоянной оценки и анализа ситуации, а с другой - не позволяет увидеть реальную картину действительности. Как правило, такие представления складываются из устоявшегося общественного мнения, слухов и теорий, не имеющих конкретного подтверждения в действительности. Таким образом, под стереотипными представлениями в данной статье будем понимать устойчивое мнение относительно какого-либо явления, человека или профессии, сформированное в условиях недостаточной информации, другими словами «житейские представления».

Дичность профессионадьного артиста, понимается нами как стереотипный образ, объединяющий в себе наиболее общие эстетические (внешний вид, одежда, невербальные средства выражения), личностные и поведенческие свойства, а также эмоционально-чувственную составляющую. Аичность актера всегда «окутана» неким «ореолом загадочности», актерская деятельность всегда порождает много вопросов, а актер возводится в ранг «звезды» определенного эталона, в связи с чем, в этой области сосредоточено множество вопросов и домыслов, что порождает исследовательский интерес. С одной стороны артист - это профессия, а с другой личность. Ни в какой другой профессии, на наш взгляд, не происходит такое слияние личного и профессионального. Профессия актера предполагает творческий процесс, а творчество без участия личности невозможно (Giserman-Kiss et al., 2020). Профессия вовлекает в себя всю личность, становясь 
одновременно и регулятором, и продуктом деятельности.

Изучение личности артиста в основном происходило в плоскости творчества и искусства. Это нашло отражение в попытках практиков театра и педагогов провести психологический анадиз дичности артиста, чьи заключения не только в психологии сценической деятельности, но и в общей психологии имеют огромную научно-практическую ценность (Вильсон, 2001). Имена К. С. Станиславского, его ученицы М. О. Кнебель, Е. Б. Вахтангова, Б. Е. Захавы, А. А. Гончарова, О. Н. Ефремова, А. В. Эфроса, и многих других стоят у истоков исследований об актере.

Наиболее яркой работой в контексте психологического осмысления личности артиста хочется отметить работу Л. С. Выготского «Психология искусства» (Выготский, 1986), где он писал, что психология актера, его жизнь, выступают не как функции его личной душевной жизни, но как явление, имеющее объективный общественный смысл и значение, служащие переходной ступенью от психологии к идеологии (Davison, Furnham, 2018).

По мнению психоаналитически ориентированных специалистов (Фромм, 2000), личность артиста характеризуется невротичностью и эксгибиционизмом, а работа для них явдяется средством сублимации и облегчения внутридичностных конфликтов (Немирович-Данченко, 1984). «Творческая личность предполагает особенно богатый материал для психологического критического анализа. Ее жизнь неизбежно переполнена конфликтами, поскольку в ней противоборствуют две силы: с одной стороны, обычный человек с его естественной потребностью в счастье, удовлетворенности и жизненной обеспеченности, а с другой безжалостная творческая страсть, волей-неволей втаптывающая в грязь все ее личные пожелания»,-писал К. Г. Юнг (Юнг, 2003).

В последние годы психологические аспекты дичности актера затрагивались в следующих психологических исследованиях: психологические особенности специадистов сферы искусства с высоким уровнем продуктивности творческого воображения (Карпова, Дикая 2016), методы сценической педагогики в решении проблем экологии человека (Грачева, 2019), особенности самопрезентации в реальном и виртуальном пространстве представителей творческих профессий (Гавриченко, 2018), психологические особенности личности актера (Курсевич, 2016), психологические и социально-психологические свойства дичности актера драматического театра (Капустина, 2016), взаимосвязь эмоционадьного интеллекта и личностных особенностей (Собкин, Лыкова, 2015).

Как мы видим, тема представлений о дичности артиста не раз подвергалась анализу, и мнения о ней весьма разнообразны, и порой противоречивы, так как сам по себе творческий процесс и творческую личность сложно проанализировать с помощью строгих научных теорий.

Однако, ни в одном исследовании не рассматривались стереотипные представления самих артистов о том, какими качествами должен обладать «типичный» 
представитель актерской профессии.

Для этого нами было проведено сравнительное исследование стереотипных представлений о дичности артиста у профессионадьных артистов и любителей сценического искусства.

\section{Методы}

Для изучения стереотипных представлений о личности профессионадьных артистов было проведено эмпирическое исследование.

Цель: сравнить стереотипные представления о личности профессионального артиста у представителей профессии и любителей сценического искусства.

Гипотеза исследования: стереотипные представления о дичности профессионального артиста у представителей профессии и у любителей сценического искусства будут иметь значительные отличия.

Для реализации указанных задач и подтверждения выдвинутой гипотезы нами была выбрана «Анкета биполярных профилей» Т. Г. Стефаненко (в модификации Гришиной А. В., Комеровой Н. Е.) - эта методика состоит из 24 пар противоположных качеств. В классическом варианте она исподьзовалась для выявления этнических авто- и гетеростереотипов респондентов путем приписывания качеств представителям этнических групп. В целях нашего исследования данная методика была модифицирована для исследования личностных качеств профессиональных артистов, некоторые качества были заменены на более «типичные» для описания личности артиста. Для сравнительного анализа полученных данных выбран статистический критерий U-Манна-Уитни.

Эмпирической базой исследования выступило государственное автономное учреждение культуры Ростовской области «Ростовский академический театр драмы имени Максима Горького».

Объектом исследования выбраны:

- Артисты, имеющие профильное образование по специальности «Актерское искусство» в количестве 30 человек;

- Дюбители сценического искусства (зрители), посещающие театрализованные представления не менее 4 раз в год - 30 человек.

Исследование проводилось в четыре этапа: научно - теоретический, организационный, психодиагностический и констатирующий.

\section{Результаты}

Для определения стереотипов проводилась интерпретация результатов по указанной схеме (Гришина, Зеленов, Аунин, 2016): 1) По каждому из представленных 54 качеств вычислялось среднее значение по группе; 2) Были выделены 8 качеств с наивысшим баллом, т. е. с высшей степенью выраженности указного признака у представителей исследуемой группы, по мнению группы 
респондентов; 3) Были выделены 8 качеств с наименьшим балиом, т. е. со слабой степенью выраженности указного признака у представителей исследуемой группы, по мнению группы респондентов; 4) Дана описательная характеристика полученных представлений, состоящих из условно «положительных» и «отрицательных» качеств.

Таким образом, нами были получены следующие условно «положительные качества» с наивысшей степенью выраженности:

\section{1. Оптимизм}

2. Высокий эмоциональный интеллект

3. Доброта

4. Способность мыслить творчески

5. Трудолюбие

6. Эмоциональная восприимчивость

7. Стремление к успеху

8. Высокая самооценка

К условно «отрицательным» качествам с наименьшей степенью выраженности респонденты причислили следующие:

1. Примат материальных ценностей

2. Тщеславие

3. Пессимизм

4. Злобность

5. Безраздичие к успеху

6. Лень

7. Неуверенность в себе

8. Равнодушие к достижениям

Полученные с исподьзованием данного подхода результаты представлены в диаграммах (Рис. 1 и Рис. 2).

Таким образом, представления об условно «положительных качествах», присущих дичности профессионального артиста по мнению респондентов-представителей профессии и любителей сценического искусства относительно схожи. Например, респонденты обеих групп считают, что профессиональному артисту присущи такие качества, как оптимизм, трудолюбие, высокий эмоциональный интеллект, способность мыслить творчески. На основании сравнительного анализа полученных данных с помощью статистического критерия U-Манна-Уитни, усредненный показатель по шкале «высокая самооценка» $\left(\mathrm{p}<0,01 ; \mathrm{U}_{\text {эмп. }}=259,5\right)$ выявил значимые раздичия в мнениях респондентов, интересно, что сами артисты оценивают ее гораздо менее присущей артисту-профессионалу, чем любители сценического искусства. Данный показатель, на наш взгляд, можно объяснить постоянными творческими поисками, сменой ролей, постоянным оцениванием «качества» актерской игры режиссерами и театральными критиками. 


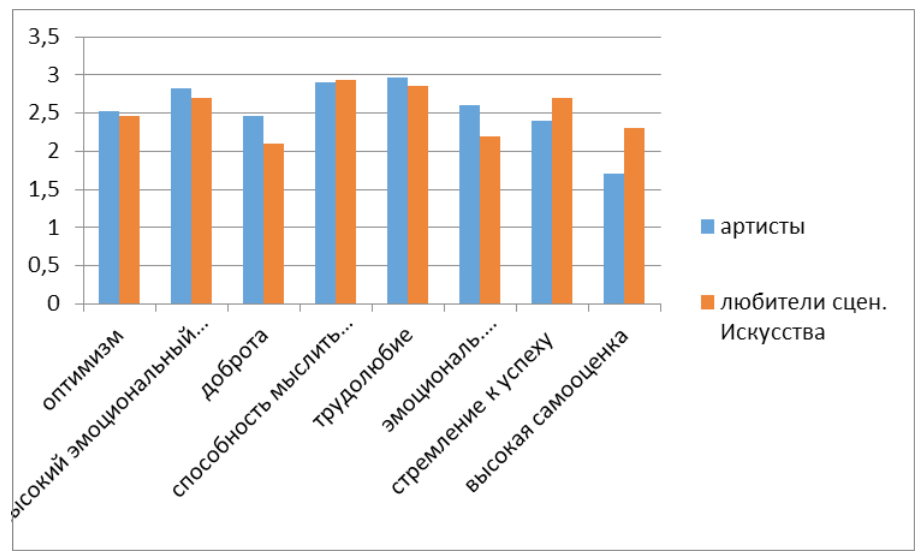

Рисунок 1. Сравнительные представления о условно «положительных» качествах ^ичности профрессионального артиста у представителей профрессии и ^юбителей сценического искусства

Также, актеры-профессионалы считают качество «эмоциональная восприимчивость» более выраженной у профессионального актера, чем любители сценического искусства. Возможно, здесь артисты воспроизводят свои переживания по поводу востребованности в профессии и ожидания признания. Значимых раздичий по данной шкале не выявлено.

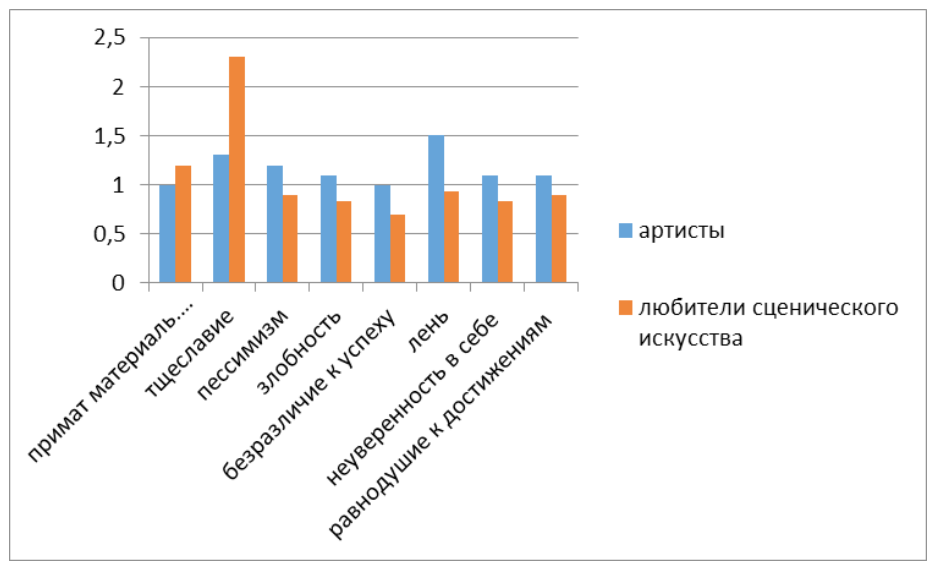

Рисунок 2. Сравнительные представления о условно «отрицательных» качествах мичности профрессионального артиста у преАставителей профрессии и любителей сценического искусства 
В результате полученных данных, оценка условно «отрицательных» качеств обеими группами респондентов также была достаточно однородна, но заслуживает внимания следующие качества, мнения о которых у представителей профессии и любителей сценического искусства значительно разнятся.

Так, «тщеславие» по мнению профессиональных актеров присуще им гораздо в меньшей степени, чем указывает другая группа. Согласно критерию U-Манна-Уитни ( $\left.\mathrm{p}<0,01 ; \mathrm{U}_{\text {эмп. }}=211\right)$, раздичия в мнениях респондентов относительно данного качества статистически значимы. Возможно, зрители склонны считать, что выбор профессии артиста обусловлен желанием человека получить признание и известность, а артисты считают это способом реализации творческого потенциала.

Интересно, что профессиональные артисты ставят большие баллы, по качеству «лень», представителю актерской профессии, чем любители сценического искусства, которые практически искдючают присутствие этого качества у артистов. Раздичия ( $<<0,01 ;$ Чэмп.= 276,5) по данному показателю в группах респондентов находится в зоне значимости. Данное обстоятельство может говорить о самокритичности артистов и стремлении к идеалу в профессии, в связи с этим артисты часто употребляют выражение «служение театру» (Liron, Raindell \& Alon, 2018). Также представители творческой профессии большими балиами, чем вторая группа, наделяют присутствие у артиста таких качеств, как злобность, равнодушие к достижениям, пессимизм. Значимых раздичий по этим качествам не выявлено. В связи с тем, что противоположные качества имеют очень высокие оценки, а эти не искдючаются подностью, но в менее выраженной степени говорит о наличии некоей «двойственности» в отношении к личности артиста.

\section{Обсуждение резудьтатов}

Итак, в данной статье дан обзор исследований в области стереотипных представлений, личности профессионального артиста, проведено сравнительное исследование среди двух групп респондентов на выявление схожих представлений о дичностных качествах представителей актерской профессии. Так, обе группы считают, что артист оптимистичен, обладает высоким уровнем эмоционадьного интеллекта, способен творчески мыслить, трудолюбив, эмоционадьно восприимчив и стремится к успеху. Достоверно раздичны мнения респондентов относительно высокой самооценки. К наименее присущим профессиональному артисту качествам отнесены: лень, неуверенность в себе, злобность, примат материальных ценностей, пессимизм и тщеславие. Полученные раздичия по показателям высокая самооценка, тщеславие и лень могут указывать на то, что артисты в своей профессиональной деятельности часто сталкиваясь с критикой и оцениванием со стороны, и сами становятся критичны к себе и к профессии. 
Проведенное исследование показало, что стереотипные представления имеют большое влияние на восприятие личности другого человека, сквозь призму его профессии. Эти представления обладают относительной устойчивостью, поскольку и представители профессии, и любители сценического искусства, приписывают схожие качества «типичному» профессиональному артисту, однако, значимые раздичия все же есть. Таким образом, считаем, что гипотеза исследования частично подтвердилась.

\section{Авторы заявляют об отсутствии конфликта интересов.}

\section{Дитература}

Вильсон, Г. (2001). Психология артистической деятельности: таланты и поклонники. М.: Когито-Центр.

Выготский, А. С. (1986). Психология искусства. 2-е изд. испр. и доп. М.: Искусство.

Гавриченко, О. В. (2018). Особенности самопрезентации в реальном и виртуальном пространстве представителей творческих профессий. Вестник РГГУ. Серия: Психология. Педагогика. Образование, 4(14), 96-114.

Грачева, А. В. (2019). Опыт применения методов сценической педагогики в решении проблем экологии человека. Социальный театр. Вестник Академии русского балета им. А.Я. Вагановой, 1(60), 111-126.

Гришина, А. В., Зеленов, А. А., Аунин, С. А. (2016). Диагностика влияния этнической идентичности на формирование этнических ауто- и гетеростереотипов у беженцев и вынужденных переселенцев из регионов локальных военных конфликтов и принимающего населения. М.: КРЕДО.

Капустина, А. Н. (2016). Профессиональные и социально-психологические свойства дичности актёра драматического театра. Universum: психология и образование, 7(25), 1-11.

Карпова, В. В., Дикая, А. А. (2016). Индивидуально-психологические особенности специалистов сферы искусства с высоким уровнем продуктивности творческого воображения. Российский психологический журнал, 13(2), 71-87.

Курсевич, Н. И. (2016). Психологические аспекты создания артистами сценических образов. Акмеология, 4(60), 96-99.

Немирович-Данченко, В. И. (1984). О творчестве актера. М.: Искусство.

Собкин, В. С., Аыкова, Т. А. (2015). Взаимосвязь эмоционального интеллекта и личностных особенностей (по материалам обследования студентов театрадьного колледжа). Наццинальный психологический журнал, 2(18), 56-65.

Фромм, Э. (2000). Ради любви к жизни. М.: АСТ.

Юнг, К. Г. (2003). Дух в человеке, искусстве и литературе. Минск: Харвест.

Davison, M., Furnham, A. (2018). The personality disorder profile of professional actors. Psychology of Popular Media Culture, 7(1), 33-46. doi: https://doi.org/10.1037/ppm0000101 
Giserman-Kiss I., Gorenstein M., Feldman E., Rowe, M., Grosman, H., Weissman, J., Rouhandeh, A., Wilkinson, E., Meyering, K., Durkin, A., Isenstein, E., Kolevzon, A., Buxbaum, J. D., Siper, P. M. (2020). The immersive theater experience for Individuals with autism spectrum disorder. Journal of Autism and Developmental Disorders, 50, 1073-1080. doi: https://doi.org/10.1007/s10803-019-04284-7

Liron, Y., Raindel, N., Alon, U. (2018). Dramatic action: A theater-based paradigm for analyzing human interactions. PLoS ONE, 13(3), e0193404. doi: https://doi. org/10.1371/journal.pone.0193404

\section{References}

Davison, M., Furnham, A. (2018). The personality disorder profile of professional actors. Psychology of Popular Media Culture, 7(1), 33-46. doi: https://doi.org/10.1037/ ppm0000101

Fromm, E. (2000). For the love of life. Moscow: AST. (in Russ.).

Gavrichenko, O. V. (2018). Features of self-presentation in the real and virtual space of representatives of creative professions. Vestnik of Russian State University for the Humanities. Series: Psychology. Pedagogy. Education, 4(14), 96-114. (in Russ.).

Giserman-Kiss I., Gorenstein M., Feldman E., Rowe, M., Grosman, H., Weissman, J., Rouhandeh, A., Wilkinson, E., Meyering, K., Durkin, A., Isenstein, E., Kolevzon, A., Buxbaum, J. D., Siper, P. M. (2020). The immersive theater experience for Individuals with autism spectrum disorder. Journal of Autism and Developmental Disorders, 50, 1073-1080. doi: https://doi.org/10.1007/s10803-019-04284-7

Gracheva, L. V. (2019). Experience of using methods of stage pedagogy in solving problems of human ecology. Social Theater. Vestnik of the Vaganova Academy of Russian Ballet, 1(60), 111-126. (in Russ.).

Grishina, A. V., Zelenov, A. A., Lunin, S. L. (2016). Diagnostics of the influence of ethnic identity on the formation of ethnic auto-and heterostereotypes in refugees and internally displaced persons from the regions of local military conflicts and the host population: an educational and methodological manual. Moscow: CREDO. (in Russ.).

Jung, K. G. (2003). The spirit in man, art and literature. Minsk: Harvest. (in Russ.).

Kapustina, A. N. (2016). Professional and socio-psychological properties of the personality of a drama theater actor. Universum: Psychology E Education, 7(25), 1-11. (in Russ.).

Karpova, V. V., Dikaya, L. A. (2016). Individual psychological characteristics of art specialists with a high level of productivity of creative imagination. Russian Psychological Journal, 13(2), 71-87. (in Russ.).

Kursevich, N. I. (2016). Psychological aspects of creating stage images by artists. Acmeology, 4(60), 96-99. (in Russ.).

Liron, Y., Raindel, N., Alon, U. (2018). Dramatic action: A theater-based paradigm for analyzing human interactions. PLoS ONE, 13(3), e0193404. doi: https://doi. org/10.1371/journal.pone.0193404 
ОБЩАЯ ПСИХОЯОГИЯ, ПСИХОЯОГИЯ АИЧНОСТИ, ИСТОРИЯ ПСИХОЛОГИИ

Nemirovich-Danchenko, V. I. (1984). About the work of the actor. Moscow: Iskusstvo. (in Russ.).

Sobkin, V. S., Lykova, T. A. (2015). The relationship of emotional intelligence and personal characteristics (based on the survey of students of the theater College). National Psychological Journal, 2(18), 56-65. (in Russ.).

Vygotsky, L. S. (1986). Psychology of Art. 2nd ed. rev. \& add. Moscow: Iskusstvo. (in Russ.).

Wilson, G. (2001). Psychology of artistic activity: talents and fans. Moscow: CogitoCenter. (in Russ.). 